\title{
PENGUATAN PEREKONOMIAN DESA MELALUI SOSIALISASI PEMBUATAN KALDU BUBUK NON MSG DI DESA KEBONTUNGGUL, GONDANG
}

\author{
Anak Agung Sagung Alit Widyastuty ${ }^{1)}$ Atikah Atmaranti ${ }^{2)}$, Dina Eka Putri $\mathrm{S}^{3)}$ \\ ${ }^{1}$ Fakultas Teknik sipil dan Perencanaan, ${ }^{2}$ Fakultas Keguruan dan Ilmu Pendidikan, \\ Universitas PGRI Adi Buana Surabaya \\ Email.'agungalit@unipasby.ac.id, ${ }^{2}$ tikaatmaranti@gmail.com
}

\begin{abstract}
Abstrak
Kaldu bukan hal asing bagi masyarakat Indonesia karena kaldu adalah salah satu jenis rasa gurih yang mengandung ekstrak tertentu dan dengan tambahan bahan makanan lain atau tanpa bahan tambahan lainnya yang diizinkan. Kaldu instan komersial yang dijual di pasaran sebagian besar diberi tambahan Monosodium Glutamate. (MSG) sebagai penambah rasa. Penggunaan penguat rasa MSG masih menjadi perdebatan di masyarakat. Robert Ho Man Kwok pada tahun 1968, New England Journal of Medicine Chinese Restaurant Syndrome (CRS), dan kontroversi keamanan MSG yang digunakan masih berlanjut hingga hari ini meskipun Food and Drug Administration (FDA) mengeluarkan pernyataan bahwa penggunaan MSG dalam batas yang wajar batas tidak membahayakan kesehatan manusia. Hasil diseminasi Produksi Kaldu Non MSG diikuti oleh 20 ibu PKK yang mewakili setiap dusun di Desa Kebontunggul, yaitu desa Penumpang, desa Sengon, desa Jemanik dan desa Kudur. Kegiatan dimulai dari pukul 10:00 hingga 11:00. Materi yang disajikan meliputi pengetahuan umum tentang kaldu bubuk, bahaya MSG untuk anak-anak dan orang dewasa, bahan dasar kaldu bubuk non MSG, cara membuat kaldu bubuk non MSG, dan demo untuk membuat kaldu bubuk non MSG.
\end{abstract}

Kata Kunci : MSG, Penyedap, Desa Kebontunggul, Diseminasi

\begin{abstract}
Broth was not foreign to the people in Indonesia because broth is one type of savory flavor which contains certain extracts and with the addition of other food ingredients or without other added ingredients that are permitted. Commercial instant broth sold on the market was mostly given the addition of Monosodium Glutamate. (MSG) as a flavor enhancer. The use of MSG flavor enhancers was stilled a debate in the community. Dr. Robert Ho Man Kwok in 1968 New England Journal of Medicine Chinese Restaurant Syndrome (CRS), and the security controversy of used MSG still continues today even though the Food and Drug Administration (FDA) issued a statement that the use of MSG within reasonable limits does not endanger human health.The results of the dissemination of the Non MSG Powder Broth Production were participated by 20 PKK mothers representing each hamlet in Kebontunggul Village, namely Penumpang village, Sengon village, Jemanik village and Kudur village. The activity started from 10:00 to 11:00. The material presented included general knowledge about powder broth, the dangers of MSG for children and adults, the basic ingredients of non MSG powder broth, how to make non MSG powder broth, and demos for making non MSG powder broth.
\end{abstract}

Keywords : MSG, Flavoring, Desa Kebontunggul, Diseminasi 


\section{PENDAHULUAN}

Pangan merupakan salah satu kebutuhan pokok yang sangat penting dalam kehidupan manusia. Pengolahan dan pengawetan bahan makanan memiliki hubungan terhadap pemenuhan gizi masyarakat. Maka tidak mengherankan jika semua negara baik negara maju maupun berkembang selalu berusaha untuk menyediakan suplai pangan yang cukup aman dan bergizi (Sari, 2009).

Dalam kehidupan yang modern sekarang ini menjadikan perubahan gaya hidup masyarakat, termasuk perubahan pola konsumsi makanan yang lebih banyak menyukai jenis makanan cepat saji. Hal ini memacu industri pangan untuk membuat produk-produk olahan pangan siap saji, seperti makanan kaleng, makanan instan, dan lain-lain yang belakangan ini banyak dijual di pasar tradisional dan swalayan. Salah satu contoh produk olahan pangan adalah bumbu penyedap rasa (kaldu instan) (Okatvianty, $\mathrm{N}$ et al, 2017).

Kaldu bukan hal yang asing bagi masyarakat di Indonesia karena kaldu merupakan salah satu jenis savoury flavor yang mengandung ekstrak tertentu dan dengan penambahan bahan makanan lain atau tanpa bahan tambahan lain yang diizinkan. Kaldu sengaja ditambahkan pada produk pangan olahan sehari-hari untuk memperkaya rasa sebuah makanan sehingga nilai penerimaan makanan dapat menjadi lebih baik (Okatvianty, $\mathrm{N}$ et al, 2017).

Kaldu merupakan hasil dari ekstrak bahan makanan tertentu seperti daging ayam, daging sapi, seafood, dan sayuran yang ditujukan untuk meningkatkan rasa gurih pada masakan. Kaldu instan komersial yang dijual bebas di pasaran sebagian besar diberi penambahan zat Monosodium Glutamat. (MSG) sebagai penguat rasa. Penggunaan penguat rasa MSG hingga saat ini masih menjadi perdebatan di masyarakat. Permasalahan tersebut bermula dari dimuatnya surat yang ditulis oleh Dr. Robert Ho Man Kwok di New England Journal of Medicine (NEJM) tahun 1968 mengenai Chinese Restaurant Syndrome (CRS), dan kontroversi keamanan penggunaan MSG masih terus berlanjut hingga sekarang meskipun Food and Drug Administration (FDA) mengeluarkan pernyataan bahwa penggunaan MSG dalam batas yang wajar tidak membahayakan kesehatan manusia (Mosby, 2009).

MSG merupakan garam natrium dari asam glutamat yang merupakan senyawa cita rasa dan telah banyak dikonsumsi secara luas di seluruh dunia sebagai penguat cita rasa, karena penambahan MSG akan membuat makanan menjadi rasa lebih lezat (Rangkuti et al., 2012). Meskipun penggunaan MSG diperbolehkan, namun apabila berlebihan juga tidak baik untuk kesehatan. Kebanyakan konsumen atau ibu rumah tangga tidak mengetahui informasi akan dampak negatif MSG bagi kesehatan. Pengetahuan produk, pengetahuan perolehan produk dan pengetahuan pemakaian produk ini akan mempengaruhi perilaku konsumen (Blitz, Grosch, 2009).

Sebagai langkah pencegahan terhadap penyakit yang dapat muncul akibat dari penggunaan MSG yang berlebihan dan untuk memperoleh manfaat tambahan dari kaldu agar bukan semata-mata sebagai penyedap rasa, maka kaldu sehat dapat dibuat dari daging ayam, sapi, ikan, udang ataupun jamur dengan menambahkan beberapa jenis sayur untuk memberikan cita rasa yang nikmat. Pembuatan kaldu bubuk non MSG dapat menjadi solusi untuk rasa makanan yang tetap enak namun juga sehat. 


\section{METODE PELAKSANAAN}

Sosialisasi dilaksanakan di Desa Kebontunggul, Gondang, Mojokerto pada Selasa, 19 Februari 2019. Sasaran dari kegiatan ini adalah ibu-ibu PKK, karena diharapkan setelah mengetahui bagaimana cara pembuatan kaldu bubuk non MSG, ibuibu PKK dapat memproduksi seacara masal Kaldu Bubuk Non MSG ini sehingga dapat membantu meningkatkan perekonomian warga dan secara perlahan dapat merubah kebiasaan penggunaan MSG dalam masakan sehingga keluarga menjadi lebih sehat.

Pelaksanaan sosialisasi ini diawali denganpembagian handout berisi materi yang akan disampaikan, kemudian penjelasan mengenai kaldu bubuk, MSG dan bahaya MSG. Selanjutnya demo pembuatan kaldu bubuk non MSG dan sesi tanya jawab serta pembagaian sample kaldu bubuk non MSG.

\section{Alat Dan Bahan}

Alat yang digunakan dalam kegaiatan ini adalah, Kompor, Wajan anti gores, blender, spatula, pisau, oven dan loyang. Sedangkan bahan yang diperlukan dalam pembuatan kaldu bubuk non MSG adalah daging ayam yang sudah dipisahkan dari tulangnya, bawang bombay, bawang putih, daun seledri, daun bawang, wortel, ketumbar dan garam secukupnya.

\section{Cara Pembuatan Kaldu Bubuk Non MSG}

Haluskan semua bahan dengan menggunakan food processor atau blender. Usahakan jangan menambahkan air. Tambahkan 1-2 sdm minyak jika bahan sulit untuk dihaluskan. Pastikan semua bahan benar-benar halus. Pasta kaldu kemudian dimasak dengan menggunakan wajan anti lengket. Aduk-aduk selama 20-30 menit untuk mengurangi kandungan airnya. Step ini menghasilkan kaldu berbentuk pasta. Setelah proses pemasakan, ratakan pasta kaldu di atas loyang kemudian dipanggang sekitar 30 menit pada suhu $150^{\circ} \mathrm{C}$ atau sampai agak kering. Cek dan bolak balik sesekali, jangan sampai gosong. Jika sudah hampir kering, keluarkan lalu blender hingga menjadi bubuk. Lalu panggang kembali hingga benarbenar kering.

\section{HASIL DAN PEMBAHASAN}

Kegiatan Sosialisasi Pembuatan Kaldu Bubuk Non MSG diikuti oleh 20 Ibu-ibu PKK perwakilan masing-masing dusun yang ada di Desa Kebontunggul, yaitu Dusun Penunggulan, Dusun Sengon, Dusun Jemanik dan Dusun Kudur.

Pelaksanaan kegiatan dimulai dari jam 10.00 hingga pukul 11.00 dan dilanjut dengan sosialisasi mengenai pengembangan UMKM dan cara membuat batik jumput. Para peserta yang hadir diberi handout berisi penjelasan mengenai materi yang akan disampaikan. Beberapa materi yang disampaikan meliputi pengetahuan umum tentang kaldu bubuk, bahaya MSG bagi anak-anak serta orang dewasa, bahan dasar kaldu bubuk non MSG, cara pembuatan kaldu bubuk non MSG, dan demo pembuatan kaldu bubuk non MSG.

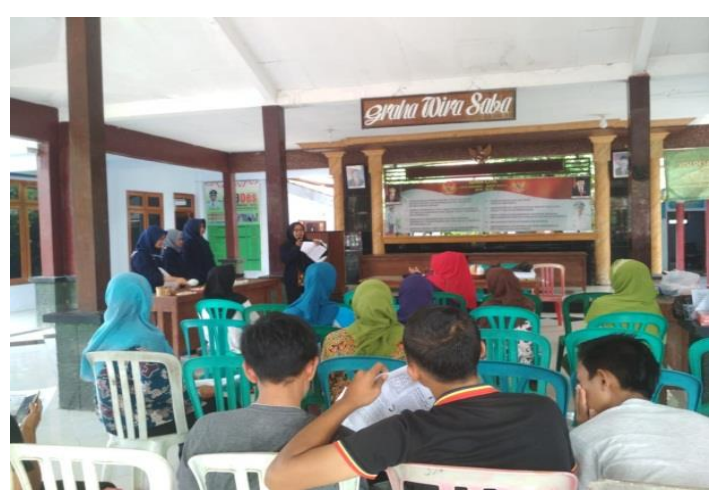

Gambar 1. Ibu-ibu PKK mendengarkan penjelasan sosialisasi mengenai materi kaldu bubuk non MSG yang disampaikan oleh mahasiswa. 
Saat ditanyai mengenai pengertian MSG, rata-rata para Ibu PKK ini menjawab bahwa MSG itu adalah micin, Masako, Royco atau sejenisnya. Dari pemahaman yang seperti ini kami mencoba meluruskan mengenai pengertian MSG kepada ibu-ibu PKK. Bahwa MSG merupakan kepanjangan dari Monosodium glutamat merupakan kandungan atau senyawa kimia yang terkandung dalam makanan yang berperan sebagai penguat rasa pada masakan. Respon positif diterima dengan mulai munculnya pertanyaan dari ibu-ibu PKK mengenai ulasan lebih mendalam mengenai pembuatan kaldu bubuk non MSG serta bahaya akan penggunaan MSG.

Setelah disampaiakn sedikit penjelasan mengenai kaldu bubuk non MSG dan sedikit pengetahuan tentang bahaya MSG, kegiatan berlanjut dengan demo cara pembuatan Kaldu Bubuk Non MSG. Dalam demo cara pembuatan kaldu bubuk non MSG ini, ibuibu PKK sangat antusias. Ibu-ibu PKK hingga rela berdiri didepan meja demo hanya untuk menyaksikan secara langsung pembuatan kaldu bubuk non MSG. Dalam demo dijelaskan dan ditunjukkan bahan apa saja yang diperlukan serta takaran bahan yang diperlukan dalam pembuatan kaldu bubuk non MSG, selain itu juga disampaikan cara atau teknik pengolahan bahan hingga bisa menjadi kaldu bubuk non MSG yang siap pakai.

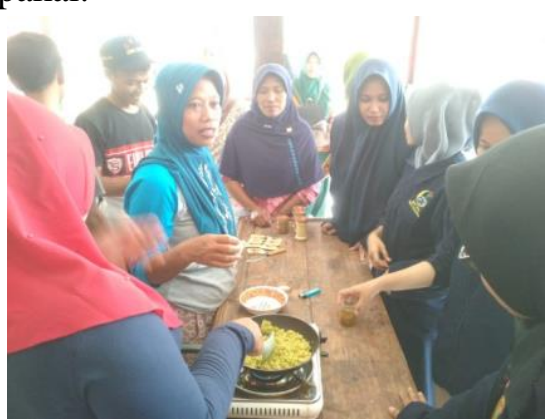

Gambar 2. Demo cara membuat kaldu bubuk non MSG, yang disaksikan oleh Ibuibu PKK Desa Kebontunggul.

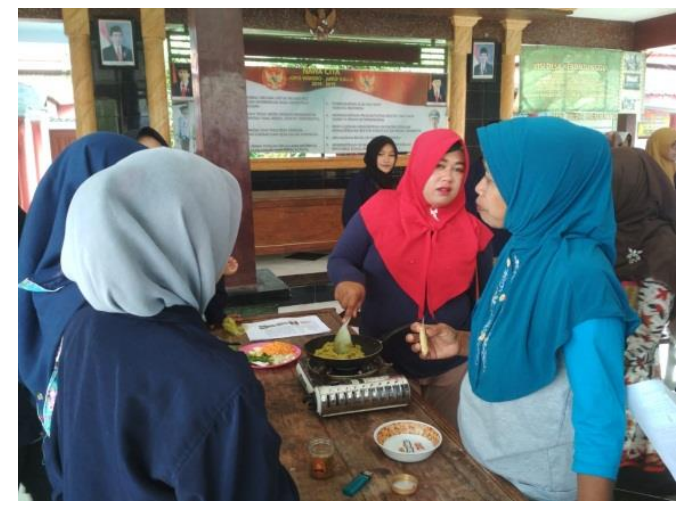

Gambar 3. Ibu-ibu PKK ikut membuat kaldu bubuk non MSG

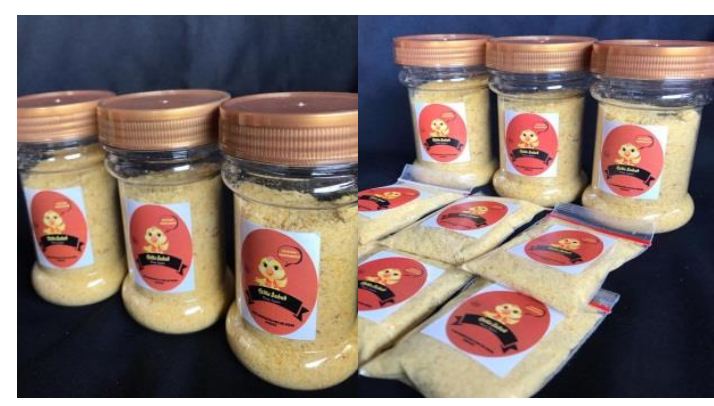

Gambar 4. Kaldu bubuk non MSG yang sudah dibuat.

Sosialisasi cara pembuatan kaldu bubuk non MSG ini diakhiri dengan mencicipi kaldu bubuk yang sudah dibuat, sesi tanya jawab dan pembagian sample kepada masing-masing peserta.

Pada sesi tanya jawab, inti pertanyaan dari ibu-ibu PKK adalah cara penggunaan kaldu bubuk non MSG dan cara penyimpanannya. Maka dijelaskan, bahwa pengguanaan kaldu bubuk ini sama saja seperti penggunaan kaldu instan dan untuk penyimpanan, kaldu bubuk non MSG dapat bertahan hingga 3 bulan dalam kemasan tertutup dan kering.

Diharapkan dari kegiatan ini para ibuibu sadar akan betapa besarnya bahaya MSG apabila berlebihan dalam penggunaannya. Mungkin bukan sekarang efek yang dirasakan, namun bila MSG sudah terakumulasi banyak dalam tubuh maka akan 
muncul gejala-gejala penyakitnya. Pada anak-anak yang berlebihan mengkonsumsi MSG dapat berakibat terjadinya kekurangan hormon thyroxin dan parathyroid yang berdampak negatif terhadap pertumbuhan tulang dan perkembnagan tubuh. Hal tersebut karena tubuh kehilangan kalsium dan fosfor (Yunita, 2014). Beberapa negara industri dan maju menetapkan konsumsi MSG yang masih bisa ditoleransi sebesar 0,3 - 1 gram per hari (Yuliarti, 2007).

Mulai sadar akan bahaya MSG dan belajar menemukan solusi pencegahannya dengan membuat kaldu bubuk sendiri. Meningkatkan daya perekonomian warga desa dengan memproduksi secara masal dan memasarkannya sebagai produk unggulan desa. Menjadi masyarakat yang sehat dan mandiri diawali dari rumah masing-masing.

\section{KESIMPULAN}

Kaldu instan komersial yang dijual bebas di pasaran sebagian besar diberi penambahan zat Monosodium Glutamat. (MSG) sebagai penguat rasa. Sebgai langkah pencegahan terhadap penyakit yang dapat muncul akibat dari penggunaan MSG yang berlebihan, Pembuatan kaldu bubuk non MSG dapat menjadi solusi untuk rasa makanan yang tetap enak namun juga sehat. Kegiatan Sosialisasi Pembuatan Kaldu Bubuk Non MSG diikuti oleh 20 Ibu-ibu PKK perwakilan masing-masing dusun yang ada di Desa Kebontunggul. Pelaksanaan kegiatan dimulai dari jam 10.00 hingga pukul 11.00. Kegiatan Sosialisasi berisi, penyampaian materi mengenai Kaldu bubuk, bahaya MSG dan demo cara pembuatan MSG. Para Ibu-ibu sangat antusias dalam kegiatan ini. Diharapkan setelah kegiatan ini kesadaran akan konsumsi pangan instan menjadi berkurang.

\section{REFERENSI}

Belitz D \& Grosch W. 2009. Food

Chemistry. Jakarta; Penebar Swadaya

Skripsi. Universitas Islam Negeri Syarif Hidayatullah Jakarta

Mosby, I. 2009. 'That Won-Ton Soup Headache': The Chinese Restaurant Syndrome, MSG and the Making of American Food, 1968-1980. Soc. Hist. Med. 22, 133-151

Octaviyanty, N Dwiloka, B Setiani, B. E. 2017. Mutu Kimiawi dan Mutu Organoleptik Kaldu Ayam Bubuk dengan Penambahan Sari Bayam Hijau. Jurnal Aplikasi Teknologi Pangan 6 (2)

Sari, Elly Nurliana. 2009. Pengaruh

Konsentrasi Dekstrin Terhadap

Komposisi Kimia dan Kestabilan

Emulsi Pasta Kaldu Nabati Berflavour(Chikenlike Falavour).

Yuliarti. 2007. Awas Bahaya Dibalik

Lezatnya Makanan. Yogyakarta; Penerbit Andi.

Yunita. 2014. Pengaruh Pengetahuan Produk terhadap Keputusan Pembelian MSG.Repository.widyatama.ac.id/xmlu i/bitsream/handle/.../Bab\%201.pdf?...5 . (Diakses, tanggal 3 Desember 2015) 
